\title{
Phylogenetic comparative methods reveal higher wing loading in ant-attended Tuberculatus aphids (Hemiptera: Aphididae)—CORRIGENDUM
}

Izumi Yao

https://doi.org/10.4039/n10-050.

Accession numbers were misplaced in Table 1 of the article by Yao (2012). The corrected table follows:

\section{Reference}

Yao, I. 2012. Phylogenetic comparative methods reveal higher wing loading in ant-attended Tuberculatus aphids (Hemiptera: Aphididae). The Canadian Entomologist, 143: 35-43. https://doi.org/10.4039/n10-050. 


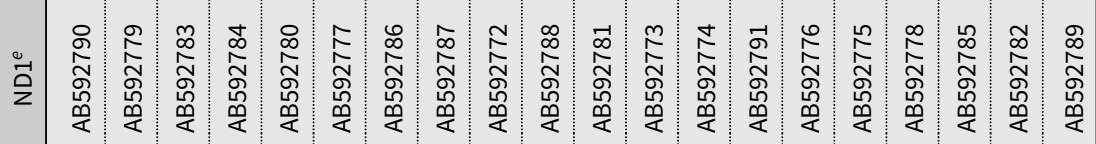

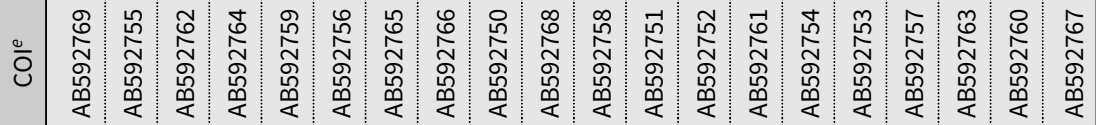

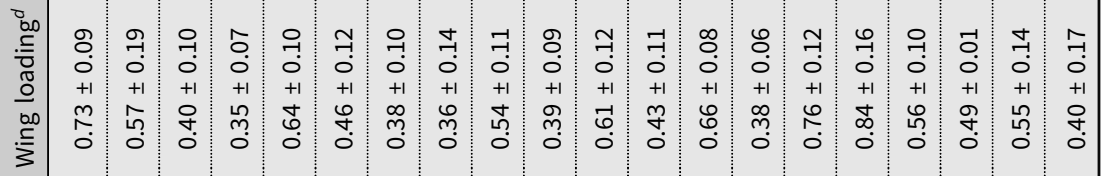

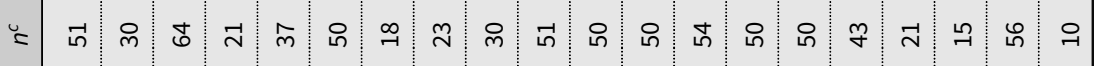

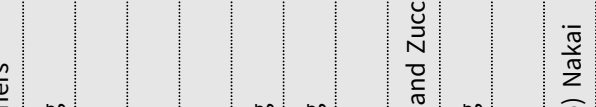



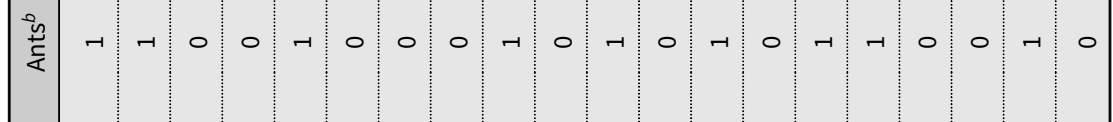

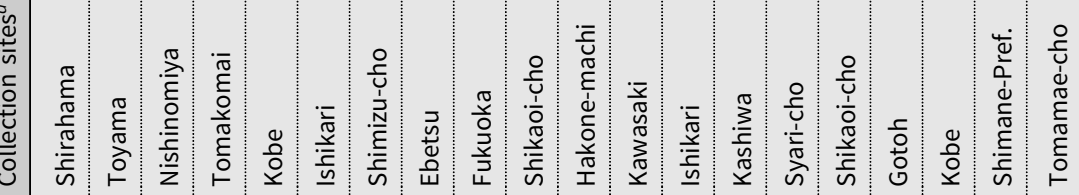

